\title{
Prognosis of 148 New Cases of Female Genital Fistula in a Multicentric Study in Niger
}

\author{
N. Idi' ${ }^{1}$ N. A. Harouna Malam Brah'1, A. Idrissa², L. Djangnikpo ${ }^{2}$, Z. Assoumana ${ }^{3}$ \\ ${ }^{1}$ FSS, Université A Moumouni, Niamey, Niger \\ ${ }^{2}$ Centre National de reference de Fistule obstetricale, Niamey, Niger \\ ${ }^{3}$ UNFPA, Niamey, Niger \\ Email: idinafi@yahoo.fr
}

How to cite this paper: Idi, N., Harouna Malam Brah, N.A., Idrissa, A., Djangnikpo, L. and Assoumana, Z. (2019) Prognosis of 148 New Cases of Female Genital Fistula in a Multicentric Study in Niger. Open Journal of Obstetrics and Gynecology, 9, 1197-1201.

https://doi.org/10.4236/ojog.2019.98116

Received: January 30, 2019

Accepted: August 20, 2019

Published: August 23, 2019

Copyright (c) 2019 by author(s) and Scientific Research Publishing Inc. This work is licensed under the Creative Commons Attribution International License (CC BY 4.0).

http://creativecommons.org/licenses/by/4.0/

\begin{abstract}
Introduction: We report anatomopathological and treatment results of new cases of obstetrical female genital fistula in main to determine the prognosis. Methodology: Multicentre prospective study over 15 months (January 1st, 2016 to March 31st, 2017) in 5 national centres of female genital fistula treatment. Patients were in all age group. Anatomopathological types were urogenital classified simple, middle and mixte (association of urogenital and recto genital). The methods of treatment were surgery and trans uretral vesical probe. We observed treated patients during 3 months. Results: 148 new cases collected. The study revealed $47.15 \%$ of urogenital fistulas were vesico-vaginal and urethro-vaginal (25.71\%). 3 cases of rectovaginal fistula including 2 cases in the lower third of the rectum and one in the upper third, 141 patients were treated. The results gave 35 cases treated by trans ureterovesical probe cured and dry, those by surgery were continent and dry (71.62\%) but 23 (15.54\%) treated but not dry, 12 (4.10\%) FGF were not closed tTab5) 7 cases not treated, one referred to urology service, one patient died before treatment and 5 perdu of view. Conclusion: Obstetric fistula remains a serious public health problem in Niger. FGF happened in all age old because of non skilled pre- and per-natal care particularly in rural area. Treatment could be improved but political prevention must be the rule.
\end{abstract}

\section{Keywords}

FGF, Treatment, Prognosis, Niger

\section{Introduction}

Rare in industrialized countries, female genital fistula (FGF) remains as a serious 
public health problem in underdeveloped countries where the health infrastructure is insufficient or non-existent as in sub-Saharan Africa Countries, South Asia and some Arab states. FGF is generally consequence of obstructive delivery labor. It deserves appropriate treatment because spontaneous closure is rare. The appropriate treatment will depend on various factors including the size and location of the fistula, the quality of the surrounding tissue, and the surgeon's experience. Therapeutic management is often difficult, sometimes disappointing (success $80 \%-95 \%$ ) [1]. We report the therapeutic results of 148 new FGF cases [2] in order to evaluate the prognosis.

\section{Methodology}

Multicentre prospective study over 15 months (January 1st, 2016 to March 31st, 2017) in 5 national centers for the therapeutic management of female genital fistula. Data were collected from focus groups, observations and pre-established individual survey form and hospital record. Anatomopathological type of FGF was defined simple if tissu around was soft and the hole not enlarged, it was middle if tissu around fistula was soft but enlarged, complexe if mixte urogenital and rectal or tissu fibrosed (Table 3) The treatment was surgical or non surgical (by transuretral vesical probe) or abstension. We observed treated patients during 3 months, the prognosis involved five elements fistula closed and dry, closed but stress incontinency, not closed, not treated, vital issu A total of 141 cases were treated, all ethic consideration respected.

\section{Results and Comments}

As we reported in previous article [2] the patients were 15 - 19 years old $(40 \%)$ of cases, married before 16 years old (55.4\%), any scholarship (89.2\%) and 77.2\% women lived outside the matrimonial home, they lived in rural area (96\%), $47.3 \%$ had the fistula at first delivery and $5.4 \%$ of recurrence cases, The duration of delivery labor was over $24 \mathrm{~h}$ (71.6\%) and finished in health facility (95.3\%) by by vacum extractor $(33.8 \%)$, Caesarean section $(23 \%)$, by laparotomy for uterin rupture (10.8\%). The stillbirths were $85.1 \%$.

The study revealed that $47.15 \%$ of urogenital fistulas were vesico-vaginal and urethro-vaginal (25.71\%). 3 cases of rectovaginal fistula, including 2 cases in the lower third of the rectum and one in the upper third. There were 5 association of rectovaginal fistula and urogenital fistula including 3 cases the same anatomical type recto-vaginal fistula of the upper third of the rectum, one of the middle third of the rectum and one of the lower third of the rectum. For the other two cases, there was a rectovaginal fistula of the upper third of the rectum associating respectively a juxta-cervical fistula and a vesico-vaginal fistula. (Table 1, Table 2 ), the vaginal flexibility was noted in $91.22 \%$ of cases. Vaginal flexibility is a best condition for the success of surgery. If diagnosed in the early postpartum days [3] recommended a conservative approach for small fistula, In this case, drainage is continued for three weeks and the fistula was then reevaluated. If the 
Table 1. Type of FGF by old age group.

\begin{tabular}{|c|c|c|c|c|c|c|c|}
\hline Type of FGF Age & $15-19$ & $20-24$ & $25-29$ & $30-34$ & $35-39$ & $\geq 40$ & Total \\
\hline recto-vaginal & 1 & 1 & 0 & 1 & 0 & 0 & 3 \\
\hline uro-génital & 56 & 26 & 18 & 14 & 19 & 7 & 140 \\
\hline Mixte & 1 & 1 & 1 & 1 & 1 & 0 & 5 \\
\hline Total & 58 & 28 & 19 & 16 & 20 & 7 & 148 \\
\hline
\end{tabular}

Table 2. Anatomic classification of urogenital FGF.

\begin{tabular}{ccc}
\hline Anatomic Classification & $\mathrm{N}$ & $\%$ \\
\hline Uretro vaginal & 36 & 25.71 \\
Para uretral & 3 & 2.15 \\
Vesico vaginal & 66 & 47.15 \\
Trigonal & 4 & 2.85 \\
Juxta cervical (blader) & 11 & 7.85 \\
Intra cervical (blader) & 2 & 1.42 \\
Circonferencial & 14 & 10 \\
Uretero vaginal & 4 & 2.85 \\
Total & 140 & 100 \\
\hline
\end{tabular}

fistula has decreased in size, in case of only urovaginal cases, a continuous transurtral vesical probe drainage test for an additional three weeks may be beneficial with a high rate of spontaneous closure. If there is no change, it is unlikely to close the fistula spontaneously, surgery is indicated [3] we did not falure in our cases. Persistent, large, or complex fistulas are best treated by surgery. [3]-[9]. A total of 141 patients were treated at first time before 50 days following diagnosis of FGF (Table 3, Table 4). We treated by prolonged (three weeks mean) drainage using a trans uretral vesical probe $35 / 141(24.82 \%)$ as early diagnosed after vaginal or cesarian in obstictive labor delivery. Surgery treatment concerned 106/141 (75.18\%), Rachis anesthesia was given for all patients and vaginal way surgery was exclusive. Any incident happened during the surgery, 7 patients were not treated because of local damage (important (vaginal fibrosis, diagnosis at end of data collection). So $91.49 \%$ patients were cured. All patients (35/35) treated by trans uretralvesical probe and $75.18 \%(106 / 141)$ by surgery, were cured dry and continent but 23 (15.54\%) were cured but not dry, 12 (4.10\%) were not closed. The treatment failed because of complex mixte FGF (Table 5). Five patients were lost of view, one patient referred to urology service for complex high level FGF and one patient died by acute anemia and denutrition before treatment; Despite the great progress by audacity and ingenuity of the surgeons, the closing of an obstetrical FGF continues to be serious problems from the 17th century to the present days, surgery is one of the most difficult and tough 
Table 3. Level of complexity of FGF.

\begin{tabular}{ccc}
\hline Complexity level & N & $\%$ \\
\hline Simple & 69 & 46.62 \\
middle & 35 & 23.64 \\
Complex & 44 & 30 \\
Total & 148 & 100 \\
\hline
\end{tabular}

Table 4. Delay before 1rst cure (number of days).

\begin{tabular}{ccc}
\hline Delay/Days & $\mathrm{N}$ & $\%$ \\
\hline $1-7$ days & 11 & 10.28 \\
$8-14$ days & 31 & 28.98 \\
$15-21$ days & 21 & 19.62 \\
$22-28$ days & 14 & 13.08 \\
$29-35$ days & 12 & 11.21 \\
$36-42$ days & 6 & 5.60 \\
$43-49$ days & 3 & 2.80 \\
$\geq 50$ days & 9 & 8.41 \\
Total & 107 & 100 \\
\hline
\end{tabular}

Table 5. Cure results.

\begin{tabular}{ccc}
\hline Result & N & $\%$ \\
\hline FGF closed and continent & 106 & 75.18 \\
FGF closed with effort incontinent & 23 & 16.31 \\
FGF not closed & 12 & 8.51 \\
Total & 141 & 100 \\
No treatment & $7 / 148$ & 4.73 \\
\hline
\end{tabular}

surgery [3]-[9]. This is due to the narrowness and depth of the operative field which limits the movements of the instruments. Long and tiring intervention is repeated with numerous failures and frequent long hospitalisation. This situation makes the management of the FGF compelling [2]-[7]. In this study, cases were treated by surgery $(82.24 \%)$ at first intervention $14.95 \%$ at second surgery and 3.73\% third time. For Idi. [1], Niger, $200557.4 \%$ of cases were cured at first operation.

Prognosis outcomes after a mean follow-up of 3 months 70.27\% FGF were closed and dry, $15.54 \%$ closed with stress urinary incontinence and $9.46 \%$ fistulas were not closed. On the other hand, 7 patients (4.73\%) had any treatment (5 were lost to follow-up and 1 died by acute anemia before any treatment and a case of upper level uretero-vaginal fistula referred in urology service).

A past study [1] in Niger in 2005, 73\% of patients were dry, $14 \%$ fistula closed 
but remained incontinent, $5 \%$ had open fistula, $2 \%$ died and $7 \%$ were lost to follow-up.

\section{Conclusion}

Obstetric fistula remains a serious public health problem in Niger. FGF happened in all age old group, particularly in rural area. For simple cases transurethral vesical probe is good approach in early diagnosed cases, but prevention by prenatal and skilled delivery assistance must be the rule.

\section{Conflicts of Interest}

The authors declare no conflicts of interest regarding the publication of this paper.

\section{References}

[1] Nafiou, I., Idrissa, A., Ghaichatou, A.K., Roenneburg, M.L., Wheeless, C.R. and Genadry, R.R. (2007) Obstetric Vesico-Vaginal Fistulas at the National Hospital of Niamey, Niger. International Journal of Gynecology and Obstetrics, 99,571-574. https://doi.org/10.1016/j.ijgo.2007.06.012

[2] Idi, N., Harouna Malam Brah, N.A., Idrissa, A., Djangnikpo, L. and Assoumana, Z. (2018) Multicentric Study of 148 New Cases of Female Genital Fistula Niger. Open Journal of Obstetrics and Gynecology, 8, 1631-1639. https://doi.org/10.4236/ojog.2018.814162

[3] Zimmern, P.E., Hadley, H.R. and Staskin, D. (1985) Genitourinary Fistulas: Vaginal Approach for Repair of Vésico-Vaginal Fistulas. Clinical Obstetrics and Gynecology, 12, 403-413.

[4] Le Duc, A., Dumurgier, Cl. and Falandry, L. (2013) Prise en charge chirurgicale des fistules obstétricales en Afrique. e-mémoires de 1 Académie Nationale de Chirurgie, $12,76-78$.

[5] Hounasso, P.P., Rochat, Ch.-H. and Kulier, R. (2008) Classification des fistules vésico-vaginales et son importance pour les données de base. Fondation Genevoise pour la Formation et la Recherche Médicales.

[6] Sanda, G., Nafiou, I. and Mounkaila, A. (2001) La fistule urogénitale au Niger, Aspects épidémiologiques et conséquences. African Journal of Urology, 7, 103-108.

[7] Mariko, S. (2000) Les fistules urogénitales, Expérience du service d'urologie de l'hôpital du point $\mathrm{G}$ à propos de 72 cas. Thèse de Médecine $\mathrm{N}^{\circ} 4$, Bamako, $48 \mathrm{p}$.

[8] Karshima, W. and Kirschner, A. (2004) The Obstetric Vesicovaginal Fistula: Characteristics of 899 Patients from Jos, Nigeria. American Journal of Obstetrics \& Gynecology, 190, 1011-1019. https://doi.org/10.1016/j.ajog.2004.02.007

[9] Ouattara, K. (2017) Problématique de la FVV obstétricale, service d'urologie, Hôpital du Point G. Bamako Mali. http://www.gfmer.org 